\title{
Geologia
}

\section{Comportamento Hidrodinâmico de Sistemas Cársticos na Bacia do Rio Betari, Município de Iporanga - SP}

\author{
José Antonio Ferrari' (ferrari.ig@uol.com.br) e Ivo Karmann² (ikarmann@usp.br) \\ 'Instituto Geológico - SMA \\ Av. Miguel Stefano 3900, CEP 04301-903, São Paulo, SP, BR \\ ${ }^{2}$ Departamento de Geologia Sedimentar e Ambiental - Instituto de Geociências - USP, São Paulo, SP, BR
}

Recebido em 27 de junho de 2007; aceito em 03 de outubro de 2007

Palavras-chave: caracterização de aqüíferos cársticos, análises de correlação e espectrais, ondeletas.

\section{RESUMO}

Técnicas estatísticas para séries temporais foram utilizadas para analisar hidrogramas de nascentes e registros de precipitação pluviométrica com o objetivo de caracterizar os fluxos de aqüíferos cársticos de um planalto do Vale do Ribeira. As análises estatísticas mostraram nascentes com características contrastantes: uma extremamente inercial, e outra que responde prontamente aos impulsos de precipitação e retorna ao estágio pré-impulsional em pouco tempo. As diferenças são explicadas a partir da geometria e dinâmica do fluxo dos sistemas (evidenciados em testes com traçadores); dos diferentes estilos de recarga identificados pelo mapeamento de feições cársticas de superfície e por modelos que relacionam o comportamento do fluxo com a estrutura da drenagem subterrânea. A nascente inercial está associada a um sistema com estrutura de drenagem distributiva e a uma recarga dispersa em pequenas bacias. A nascente diligente faz parte de um sistema caracterizado por uma estrutura de drenagem convergente (parte dela ao longo do principal sistema de cavernas do planalto) e a uma recarga concentrada em grandes pontos de captação associados às maiores bacias de recarga alóctone.

Keywords: karst aquifer, hydrology, spectral and correlation analysis, wavelets.

\begin{abstract}
Time series analyses of spring hydrographs and pluviometric data are applied in order to characterize the groundwater flow in a karst aquifer of a highland plateau in the Upper Ribeira Valley (Alto Vale do Ribeira). Two kinds of karst spring behavior were revealed based on their contrasting statistical characteristics: one is extremely inertial (the Lago spring) while the other (the Areias spring) has a fast response to rainfall events, returning quickly to the pre-impulse stage. The differences are explained on the basis of system geometry together with flow dynamics (investigated by qualitative and quantitative fluorescent dye tracer tests), by recharge volume and mechanisms (identified through the mapping of catchment areas and surface karst features) and conceptual models which relate spring flow and discharge characteristics with the internal structure of the groundwater drainage. The spring with inertial behavior is part of a distributive drainage system, and the meteoric recharge is made by small catchment basins. On the other hand, the Areias spring corresponds to a convergent drainage system (which is observed along the Areais cave system) with meteoric recharge characterized by large inputs at discrete points connected to the largest allogenic recharge areas.
\end{abstract}




\section{INTRODUÇÃO}

Os mecanismos de gênese e desenvolvimento de aqüíferos cársticos levam a formação de meios altamente descontínuos e heterogêneos não apenas na sua estrutura espacial, mas também no seu funcionamento temporal (Mangin, 1984; Labat, Ababou, Mangin, 2000). A porosidade primária associada a uma matriz intersticial geralmente é muito incipiente em aqüíferos cársticos, dominados por porosidade secundária (fraturas) ou terciária (condutos), podendo apresentar estrutura de permeabilidade hierárquica com fluxo turbulento. $\mathrm{O}$ aqüífero pode ser esquematizado como uma rede de condutos altamente permeável, quilométrica, geralmente desconhecida, “imersa” em um volume de calcário fraturado de baixa permeabilidade e conectada com uma área de descarga local (Kilary, 1998). A dualidade entre um processo de infiltração rápido, caracterizado pela rede de condutos, e uma infiltração lenta, caracterizada pela rede de fraturas, dificulta a modelagem do aqüífero. No carste, quando um poço permite caracterizações hidrogeológicas, sua validade é limitada pela grande complexidade e descontinuidade do meio (Padilla e Bosch, 1995); a noção de volume elementar representativo não pode ser utilizada (Mangin, 1994).

Apesar das limitações impostas pela anisotropia do meio, a descarga de aqüíferos cársticos costuma concentrar-se numa única ressurgência, característica que tem estimulado o uso da análise de sistemas para entender suas propriedades. A análise de sistemas em aqüíferos cársticos baseada em estatística de séries temporais foi estabelecida por Mangin (1984) e vem sendo empregada em diversos estudos (Padilla e Bosch, 1995; Laroque et al., 1998; Mathevet, Lepiller, Mangin, 2004; Zare, Nematolladhi, Sedghi, 2005 entre outros). O princípio da técnica é considerar o aqüífero como um filtro que transforma um sinal de entrada (precipitação) num sinal de saída (débito). Portanto, o grau de transformação do sinal de entrada fornece informações a respeito da natureza do fluxo no sistema. Para Mangin $(1984,1994)$, o hidrograma da ressurgência fornece uma representação integrada da rede de fluxo, podendo ser utilizado para interpretar a memória dos sistemas, que está ligada às reservas e à natureza mais ou menos carstificada do aqüífero; possibilita discernir entre sistemas bem drenados (bem carstificados) ou mal drenados (pobremente carstificados - ou fissurais).

Para Smart e Hobbs (1986), o hidrograma traduz três atributos fundamentais que governam o comportamento dos aqüíferos carbonáticos: recarga, armazenamento e transmissão. O não reconhecimento da natureza independente destes componentes resulta em interpretações errôneas quanto às características do fluxo. Segundo o modelo dos autores, o hidrograma da ressurgênica depende: a. da natureza da recarga, que pode ser concentrada (entradas grandes e localizadas) ou dispersa (entradas pequenas e disseminadas por uma grande área);

b. da capacidade de armazenamento do sistema (alta ou baixa);

c. da característica do fluxo (em condutos ou fraturas).

Diferentes combinações destes atributos podem gerar hidrogramas semelhantes a partir de processos distintos. Utilizando modelos matemáticos, Halihan e Wicks (1998) demonstraram que sistemas de condutos com múltiplas saídas ou aspectos localizados da rede de condutos (reservatórios gerados por constrições de condutos) podem gerar respostas similares àquelas atribuídas a sistemas pobremente carstificados.

Os modelos de Smart e Hobbs (1986) e de Halihan e Wicks (1998) mostram que a caracterização hidrológica do carste baseada apenas na interpretação do sinal do exutório do sistema não permite conclusões inequívocas. O hidrograma mostra o quanto um sistema altera o sinal de entrada, mas não pode explicar a causa exata desta alteração. O refinamento desta informação pode ser obtido com estudos que melhoram o conhecimento global do carste: testes com traçadores para identificar bacias subterrâneas, reconhecimento dos diferentes tipos de recarga e mapeamento dos principais sistemas de cavernas. Neste trabalho esta abordagem é utilizada para interpretar o comportamento hidrológico de duas ressurgências de um planalto carbonático do Vale do Ribeira.

\section{ÁREA DE ESTUDO}

Planaltos cársticos caracterizados por mosaicos de depressões poligonais recobertos por floresta atlântica ocorrem na Serrania Costeira do Sul do Estado de São Paulo; estão associados a uma faixa dobrada proterozóica compartimentada em blocos tectônicos seguindo um sistema de zonas de cisalhamento transcorrentes com direções NE-SW (Campanha, 1992). O planalto Lajeado-Bombas no município de Iporanga - SP, com $38 \mathrm{~km}^{2}$ de superfície encontra-se neste contexto (Figura 1). Nesta área, o bloco tectônico é ocupado pela seqüência metassedimentar de baixo grau metamórfico do Subgrupo Lajeado, composta por unidades pelíticas, psamíticas e carbonáticas, incluindo um corpo de gabro no topo. As rochas carbonáticas pertencem às Formações Bairro da Serra (com metacalcarenitos e metacalcilutitos impuros calcíticos e dolomíticos), Mina de Furnas (com metacalcarenitos e calcilutitos laminados) e Passa Vinte (metacalcarenitos dolomíticos).

O planalto carbonático encontra-se rebaixado (300-500 m de altitude) em relação às rochas pelíticas e psamíticas (localizadas entre 500-850 m) que o margeiam em alguns setores. A 


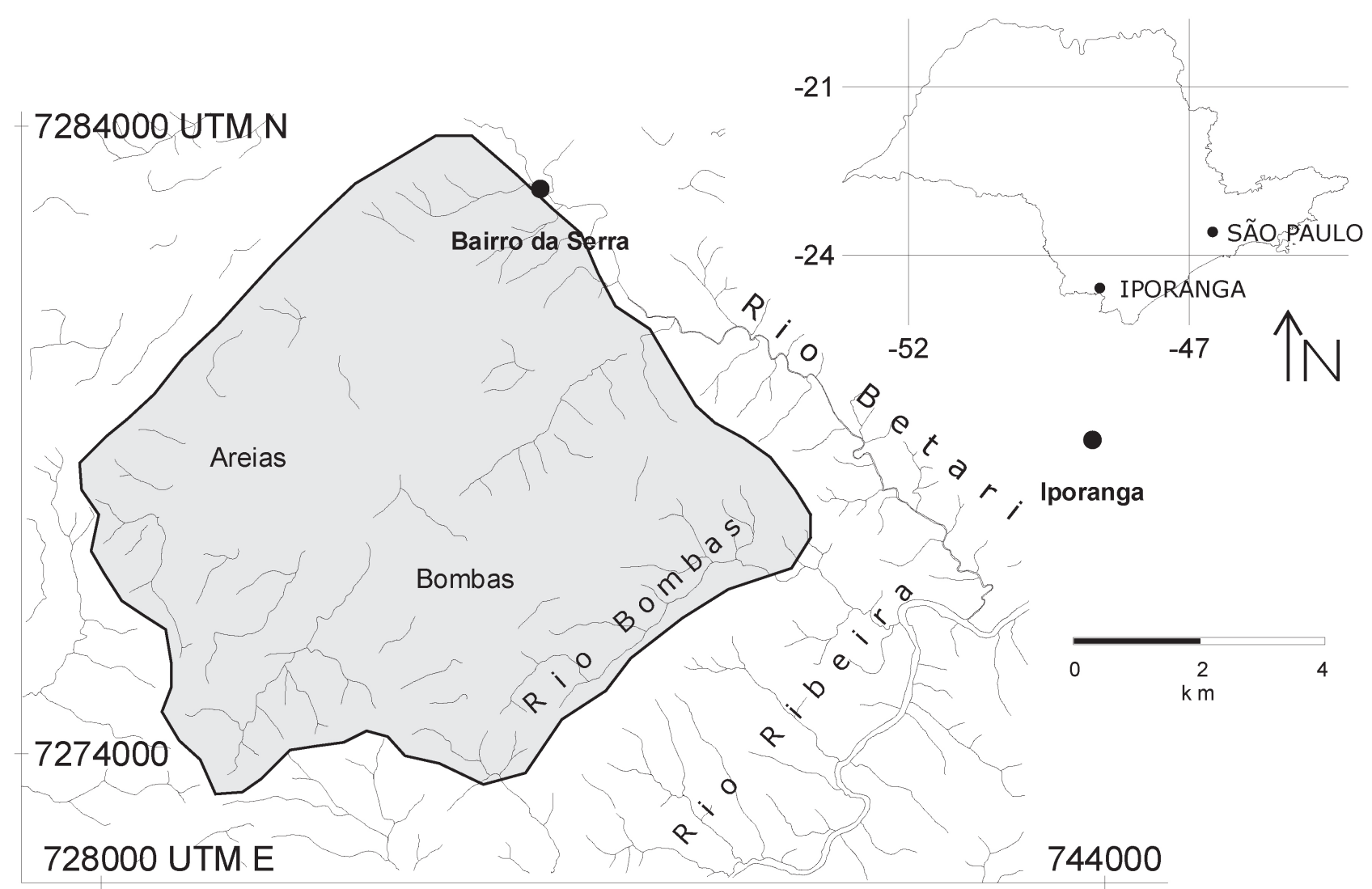

Figura 1. Localização da área de estudo.

zona de contato entre o carste e as rochas não carbonáticas é caracterizada pela presença de sumidouros e vales cegos que drenam as águas dos filitos e metassiltitos. Os fluxos concentrados de riachos perenes e efêmeros e o escoamento superficial difuso das vertentes abastecem esta zona de recarga; trinta bacias alóctones, cujas áreas variam de 0,4 a 5,5 km², dirigem suas águas para esta área. A recarga autóctone ocorre na zona do carste poligonal, em depressões cujas áreas variam de 0,04 a $2 \mathrm{~km}^{2}$, e onde prevalecem drenagens intermitentes (Karmann, 1994; Karmann e Ferrari, 2002). A Figura 2 apresenta a distribuição espacial dos diferentes tipos de recarga.

O clima quente (com temperaturas médias anuais na faixa de 20 a $22^{\circ} \mathrm{C}$ ) e úmido sem estações secas (precipitação anual na faixa dos $1.575 \mathrm{~mm}$, concentrados entre outubro e março - $1.062 \mathrm{~mm}$ ) favorece a perenidade de algumas fontes cársticas nas duas zonas de descarga que drenam o planalto: vale do rio Betari e vale do rio Bombas. Testes com traçadores (Genthner, Ferrari, Karmann, 2003) para delimitar as áreas de recarga de fontes cársticas revelaram a presença de três sistemas hidrológicos no planalto: Areias, Córrego Fundo e Bombas (Figura 3).
O sistema Areias é drenado a montante pela caverna mais importante da região (Caverna das Areias, $5.020 \mathrm{~m}$ de desenvolvimento) e tem sua ressurgência associada a uma caverna com $1.168 \mathrm{~m}$ de desenvolvimento (Caverna da Ressurgência das Areias). Um fluxo perene com uma média anual de $0,64 \mathrm{~m}^{3} / \mathrm{s}$ drena o sistema. O sistema Córrego Fundo é drenado por uma ressurgência perene e uma temporária, respectivamente ressurgência do Lago (débito médio anual de $0,28 \mathrm{~m}^{3} / \mathrm{s}$ - nunca excede $0,45 \mathrm{~m}^{3} / \mathrm{s}$ ) e do Córrego Seco (a descarga pode variar de 0 a $3 \mathrm{~m}^{3} / \mathrm{s}$ em menos de $1 \mathrm{~h}$ ). O Córrego Seco funciona como um vertedouro do sistema durante os episódios de chuvas intensas.

As ressurgências do Córrego Seco e das Areias posicionam-se nos flancos opostos de um sinclinal, nas zonas de contato com os filitos; a ressurgência do Lago localiza-se entre as duas, a menos de $700 \mathrm{~m}$ da ressurgência das Areias.

\section{MATERIAIS E MÉTODOS}

Um sistema é toda estrutura, dispositivo ou procedimento real ou abstrato que liga, num dado espaço de tempo, 


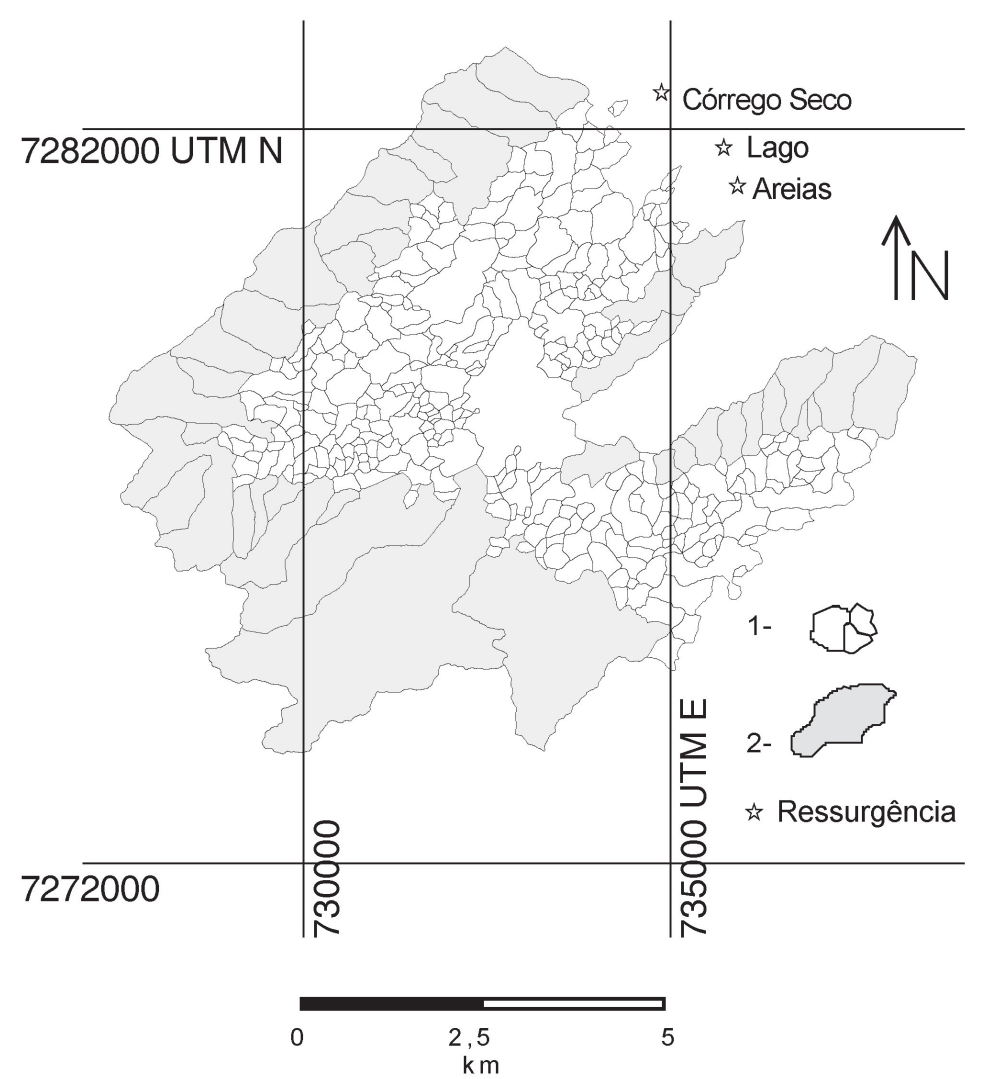

Figura 2. Depressões fechadas da zona de recarga autóctone (1) e vales cegos da zona de recarga alóctone (2) (Modificado de Karmann, 1994).

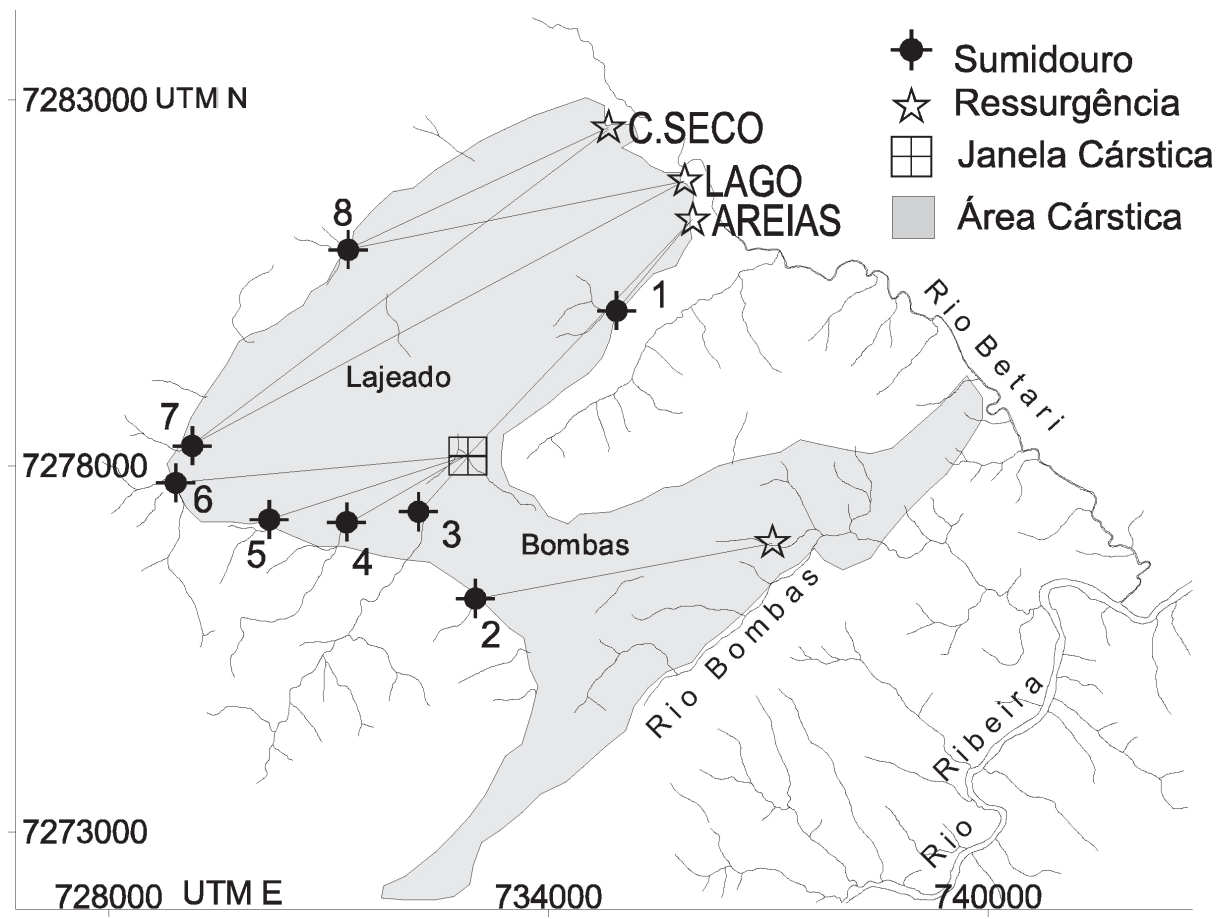

Figura 3. Sistemas hidrológicos do planalto. Sistema Córrego Fundo: ressurgências do Córrego Seco e do Lago. Sistema Areias: ressurgência das Areias. Sistema Bombas: ressurgência de Bombas. 
uma entrada, uma causa ou uma impulsão (de matéria, energia ou informação), a uma saída, um efeito ou uma resposta (de matéria, energia ou informação) (Jacquet, 1971). Para cada excitação definida para a função entrada, teremos uma resposta definida pela função de saída. Um sistema que permite a passagem de uma grandeza de entrada a uma grandeza de saída se comporta como um operador.

O termo sistema cárstico é entendido como o centro de um processo dinâmico (o fluxo), determinado por entradas (chuva) e uma saída (o débito). Segundo Mangin (1994), a noção de sistema cárstico é idêntica a de aqüífero cárstico, apenas quando a recarga do maciço é autóctone e o fluxo abastecido apenas pela precipitação (sistema unitário). No caso do planalto Lajeado-Bombas, as ressurgências não traduzem apenas o comportamento do aqüífero cárstico, mas do sistema cárstico como um todo, que engloba as bacias alóctones que injetam água no aqüífero. Estas bacias também são responsáveis pela organização da drenagem subterrânea e modulam a entrada de água no carste (sistema binário).

Para caracterizar os sistemas são utilizadas ferramentas para a análise de séries temporais, como a autocorrelação, a análise espectral, a análise de ondeletas e a correlação cruzada. A autocorrelação, a análise espectral e a correlação cruzada foram desenvolvidas por Jenkins e Watts (1968) para a análise de séries cronológicas. A análise de ondeletas foi introduzida na área de ciências da terra por geofísicos (Grosmann e Morlet, 1984) que trabalham com processamento de sinais sísmicos. Atualmente estas técnicas são amplamente utilizadas em diversos campos científicos. Mangin (1984) foi o pioneiro na utilização de análises de correlação e espectrais na investigação do fluxo subterrâneo no carste. Posteriormente, com outros colaboradores, também foi precursor do uso de ondeletas nesta mesma linha de investigação.

As séries temporais são importantes para a extração de informações a respeito da estrutura do sistema, pois trabalham com a totalidade dos impulsos por ele filtrados. A série deve ser longa o suficiente para destacar as estruturas que ela expressa e acima de tudo, não deve ser incompleta. Para estudos de hidrologia cárstica, a melhor caracterização do sistema é obtida com a análise de crônicas longas, nove anos ou mais, que exibem o comportamento médio do maciço e levam em conta a alternância de anos mais úmidos e mais secos que o normal (Mangin, 1994). No entanto, com a análise de um ano hidrológico é possível obter uma caracterização do sistema (Larocque et al., 1998). Não se pretende com este trabalho uma revisão detalhada dos métodos estatísticos para análise de séries temporais, tal tarefa já foi cumprida com excelência nos trabalhos citados anteriormente, no entanto, faz-se necessário uma breve caracterização destas ferramentas.

A autocorrelação (1) de uma série temporal põe em evidência a dependência entre os pontos da série em interva- los de tempo mais e mais espaçados; ela traduz a memória do sistema investigado. Quanto maior o efeito de um evento, mais lento será o decaimento do correlograma.

$$
\begin{aligned}
& r(k)=\frac{C(k)}{C(0)} \\
& C(k)=\frac{1}{n} \sum_{t=1}^{n-k}\left(x_{t}-\bar{x}\right)\left(x_{t+k}-\bar{x}\right)
\end{aligned}
$$

onde: $r_{k}$ é o coeficiente da autocorrelação; $k$ é o tempo de defasagem "lag" ( $\mathrm{k}$ varia de 0 até $\mathrm{m}$ ), quando $k=0, r_{k}=1 ; C_{k}$ é a autocorrelação da série para um determinado valor de $k$; $n$ é o comprimento da série temporal; $x$ é o valor de um evento; $\bar{x}$ é a média dos eventos; $m$ é o ponto de corte.

O ponto de corte $(m)$ determina o intervalo analisado e é escolhido para circunscrever um dado comportamento, como efeitos anuais ou outros efeitos sentidos em longo prazo. Pesquisa empírica (Mangin, 1984) mostrou que os melhores resultados são alcançados para $\mathrm{m} \leq \mathrm{n} / 3$; para $\mathrm{a}$ análise de um ciclo hidrológico, $m=122$ dias.

Do ponto de vista do aqüífero cárstico (sistema unitário), a velocidade de decaimento do coeficiente de autocorrelação é interpretada como uma característica da capacidade de estocagem do sistema. Quanto maior a capacidade de estocagem, maior o tempo de esvaziamento dos seus reservatórios, resultando num lento decaimento do correlograma. O decaimento lento também aponta para sistemas mal drenados, pouco carstificados; enquanto que o decaimento rápido é característica de sistemas muito bem drenados ou bem carstificados (Mangin, 1984, 1994; Larocque et al., 1998). Para comparar diferentes sistemas, é utilizado como índice, o tempo decorrido para se atingir o coeficiente de autocorrelação 0,2 . O valor 0,2 foi definido a partir da observação de correlogramas obtidos para diferentes sistemas cársticos. Este parâmetro é chamado de efeito de memória e quanto maior o seu valor, menos carstificado é o sistema (Mangin, 1984).

Levando em conta o modelo de Smart e Hobbs (1986), o decaimento lento também pode ser conseqüência de recargas dispersas e/ou armazenamento significativo, independente do fluxo ocorrer em condutos ou fraturas. De acordo com o modelo de Halihan e Wicks (1998), reservatórios em sistemas de condutos ou sistemas com múltiplas saídas também podem apresentar um decaimento lento no correlograma.

Outra técnica utilizada para a análise das séries temporais é a análise espectral, ou função de densidade espectral. Nesta análise a série temporal é transformada e analisada no 
domínio das freqüências. Esta transformação é interessante, pois na maioria dos casos, permite um melhor entendimento dos componentes da série temporal, uma vez que eles são bem separados. Segundo Mangin (1984), foi demonstrado que a transformação da série temporal para o domínio das freqüências corresponde à decomposição da variância dos componentes da série temporal expressos em freqüência. A decomposição da variância é obtida pela transformada de Fourier do correlograma. A fórmula usada nesta transformação (3) foi proposta por Jenkins e Watts (1968):

$$
S(f)=2\left[1+2 \sum_{k=1}^{m} D(k) r(k) \cos (2 \pi f k)\right]
$$

onde: $S_{f}$ é a densidade espectral; $k$ é o tempo de deslocamento; $f$ é a freqüência, $f=j / 2 m(\mathrm{j}=1 . . \mathrm{m}) ; D(k)$ é uma função de ponderação necessária para assegurar que os valores de $S_{f}$ estimados não sejam tendenciosos. Para Mangin (1984), a função de Tukey (4) mostrou-se a mais eficiente:

$$
D(k)=\frac{\left(1+\cos \pi \frac{k}{m}\right)}{2}
$$

Após o cálculo de $S_{f}$ é plotado um gráfico de freqüências versus densidade espectral. Cada pico observado no gráfico indica a presença de um fenômeno periódico. Gráficos que apresentam picos significativos próximos às baixas freqüências, indicam sistemas relativamente menos drenados. Quando valores elevados de densidade espectral posicionam-se em freqüências próximas de zero, a existência de fenômenos periódicos mais longos que a série temporal analisada podem estar presentes. A intensidade do espectro pode ser insignificante em altas freqüências, indicando uma falta de informações úteis nesta faixa. A freqüência a partir da qual esta condição aparece é chamada freqüência de corte. Quanto mais baixa a freqüência de corte, mais inercial o sistema e, portanto, menos drenado.

Para caracterizar o sistema, utiliza-se a noção de largura de banda (área do espectro dividido por seu valor máximo), a qual caracteriza o intervalo de freqüência no qual a relação entrada-saída ocorre. Utilizando este conceito, é possível obter uma indicação do tempo de regulação, que define a duração da influência do sinal de entrada e dá uma indicação do comprimento do impulso-resposta do sistema. O tempo de regulação é obtido dividindo o valor de $f(0)$ por 2 ; quanto maior o tempo de regulação, mais inercial é o sistema.

A autocorrelação e a análise espectral fornecem características sobre a hidrodinâmica do sistema, computando o tempo de influência dos pulsos de entrada. Uma vez que estas análises operam globalmente, não é possível obser- var a variabilidade temporal em diferentes escalas de resolução e as relações entre processos de diferentes escalas. Esta limitação pode ser superada com a análise de ondeletas. Esta ferramenta fornece informação sobre a variabilidade dos processos em diferentes escalas de resolução de forma compacta e concisa (Labat, Ababou, Mangin, 2000). O objetivo básico do uso de ondeletas é alcançar uma representação completa de fenômenos localizados e transientes que ocorrem em diferentes escalas de tempo. A principal propriedade desta ferramenta é tornar possível a distinção de sinais cuja estrutura não pode ser identificada pela análise espectral.

A ondeleta de Morlet é uma função de ondeleta não ortogonal, consiste de uma onda plana modulada por uma Gaussiana:

$$
\psi_{0}(\eta)=\pi^{-1 / 4} e^{i \omega_{0} \eta} e^{-\eta^{2} / 2}
$$

onde $\omega_{0}$ é uma freqüência não dimensional e $\eta$ é o tempo não dimensional. A transformada de ondeleta contínua de uma seqüência discreta $X_{n}$ é definida como a convolução de $X_{n}$ com uma versão escalada e transladada de $\psi_{0}(\eta)$ :

$$
W_{n}(s)=\sum_{n^{\prime}=0}^{N-1} x_{n}{ }^{\prime} \psi *\left[\frac{\left(n^{\prime}-n\right) \delta t}{s}\right]
$$

onde o (*) indica o complexo conjugado. Variando a escala (s) da ondeleta e transladando ao longo do tempo (n), é possível construir uma figura mostrando a amplitude versus a escala de qualquer feição e como esta amplitude varia no tempo (Torrence e Compo, 1998). A Figura 4 exemplifica a diferença entre a análise espectral de Fourier e o espectro da ondeleta de Morlet.

As abordagens anteriores analisam como o sistema transforma o sinal de entrada de forma global, ou com a discriminação de fenômenos observados em diferentes escalas de tempo. A função de correlação cruzada (FCC) é usada para analisar as relações entre as séries de entrada e de saída, para $k>0$ :

$$
\begin{aligned}
& r_{x y}(k)=\frac{C_{x y}(k)}{\sigma_{x} \sigma_{y}} \\
& C_{x y}(k)=\frac{1}{n} \sum_{t=1}^{n-k}\left(x_{t}-\bar{x}\right)\left(y_{t+k}-\bar{y}\right)
\end{aligned}
$$

onde $C_{x y}(k)$ é o correlograma cruzado, e $\sigma_{x}$ e $\sigma_{y}$ são os desvios padrões das séries temporais. $\mathrm{O}$ índice $k$ determina o deslocamento entre as séries para o cálculo da correlação. 
A

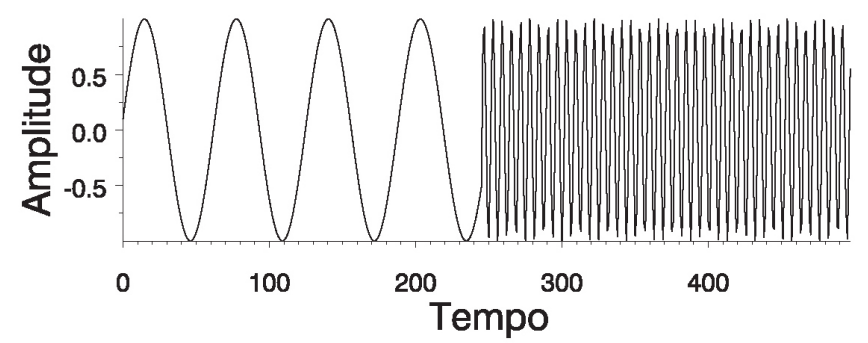

C

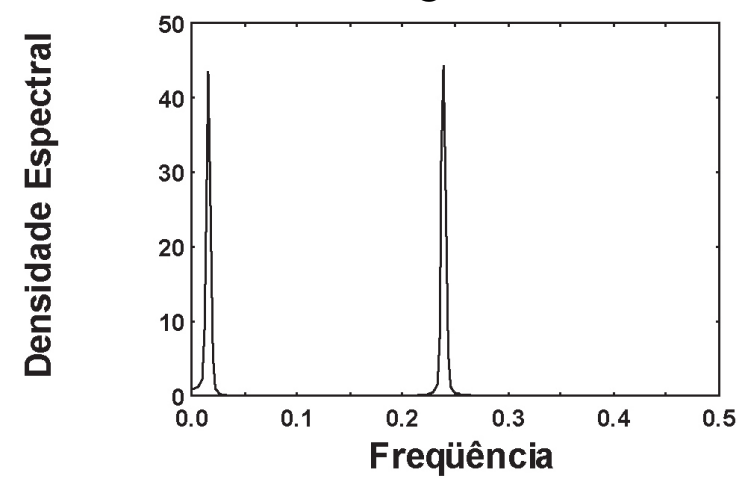

E

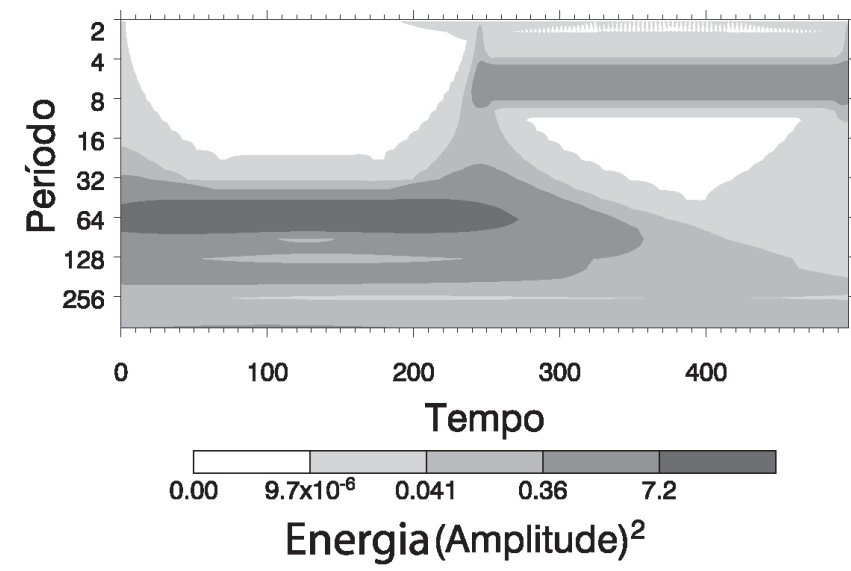

B

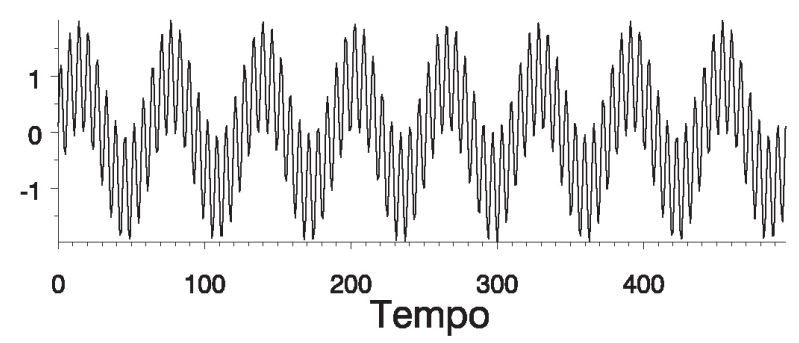

D

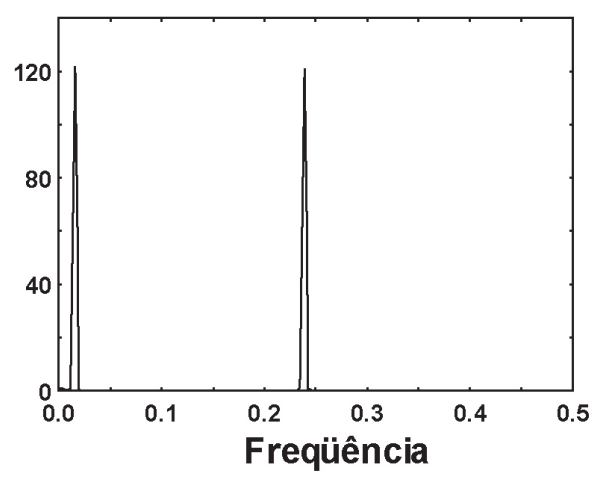

$\mathbf{F}$

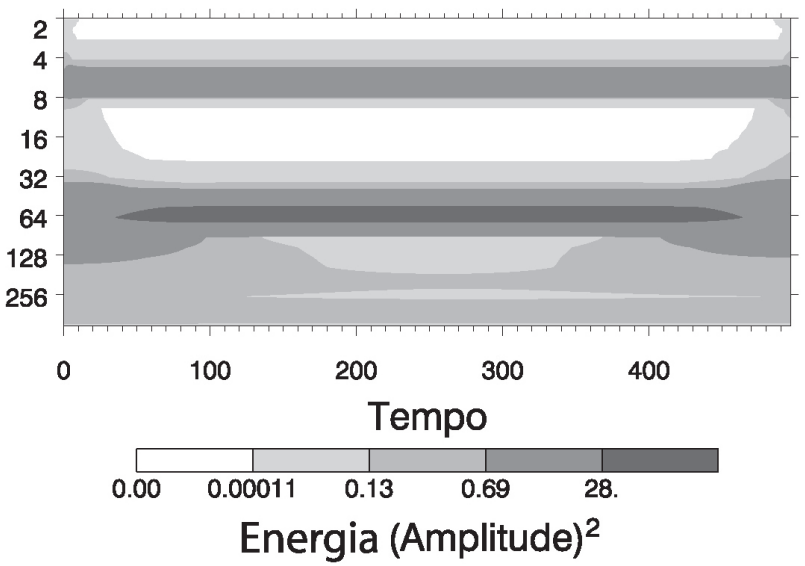

Figura 4. Diferença entre a análise espectral de Fourier e o espectro de ondeleta de Morlet. Dois sinais senoidais (A e B) compostos por duas freqüências distintas são apresentados. Em A, as duas freqüências estão temporalmente localizadas e em B, ambas as freqüências estão presentes durante todo intervalo de observação. Os respectivos espectros de Fourier (C e D) são muito semelhantes e não permitem distinguir as estruturas dos sinais. Diferentemente, os coeficientes das ondeletas (E e F) exibem claramente a discrepância dos dois componentes. A escala de cinza representa os coeficientes das ondeletas, a energia do sinal; os tons mais claros indicam os valores mais baixos. Note que a energia não leva em conta apenas a amplitude do sinal, mas a área que ele ocupa na série. 
Se a série de entrada é aleatória, a função de correlação cruzada, $r_{x y}(k)$ corresponde à resposta impulsionante do sistema. A FCC fornece informação das relações causais ou não causais entre a entrada e a saída e também da importância destas relações. Esta função não é simétrica, e se $k<0, x$ substitui $y$ e vice-versa nas equações (7) e (8). Se $r_{x y}(k)>0$ para $k>0$, a entrada influencia a saída, enquanto se $r_{x y}(k)>0$ para $k<0$, a saída influencia a entrada. Uma função de correlação cruzada perfeitamente simétrica, centrada em $k=0$, indica que os sinais de entrada e saída reagem ao mesmo tempo a um terceiro sinal independente. Neste caso, a entrada não influencia a saída. A defasagem é definida como o tempo decorrido entre $k=0$ e o valor máximo de $r_{x y}(k)$. Compreender as defasagens entre entradas e saídas em aqüíferos cársticos é uma informação útil, pois fornece uma estimativa do tempo de transferência do pulso e tempo de viagem de partículas através do sistema.

\section{O MONITORAMENTO HIDROLÓGICO}

Para a caracterização dos sistemas hidrológicos foram instalados instrumentos de monitoramento em diferentes pontos do planalto. A aquisição dos impulsos de chuva foi obtida com um pluviômetro com resolução de $0,2 \mathrm{~mm}$, acoplado a um registrador digital de eventos. O equipamento foi instalado próximo ao ponto identificado na Figura 2 como janela cárstica. Registradores digitais do nível d’água foram instalados na ressurgência da Areias e na ressurgência do Lago.

Os valores de nível d’água adquiridos com resolução de 10 min, foram convertidos para valores de vazão, a partir das curvas-chave estabelecidas para os pontos monitorados. Para a caracterização dos fluxos utilizando a autocorrelação, a análise espectral e a análise de ondeletas, os valores de descarga foram convertidos para débito médio diário. Para a análise da relação impulso-resposta a partir da FCC, os dados de chuva e de débito foram convertidos respectivamente para precipitação total horária e vazão média horária. A Tabela 1 sintetiza os dados coletados durante o desenvolvimento do trabalho.

\section{RESULTADOS}

Os gráficos da Figura 5 exibem os resultados dos monitoramentos hidrológicos realizados no planalto Lajeado-Bombas. Os valores apresentados são a precipitação total diária e vazão média diária. Conforme destacado na Tabela 1, os dados foram obtidos em anos hidrológicos distintos, no entanto, este fato não impede a comparação entre os sistemas. Os totais pluviométricos dos dois anos hidrológicos não apresentam diferenças significativas (no período 2000-2001 o total precipitado foi de $1.505 \mathrm{~mm}$ e no período 2002-2003, 1.535 mm), e os padrões de distribuição de impulsos de chuva não são contrastantes. O valor médio da precipitação diária (considerando apenas os dias chuvosos) também apresenta pequena variação, no período 2000-2001 a precipitação média diária foi de 7,7 mm com coeficiente de variação de 1,4 e no período 2002-2003, 7,2 mm com variação de 1,8. Assim, para fins de comparação, considera-se que os sinais de entrada registrados nos dois períodos não apresentam variação suficiente para sobrepor a assinatura espectral dos sistemas monitorados.

O hidrograma das Areias apresenta características similares ao escoamento observado em rios de superfície. O hidrograma do Lago apresenta uma forte influência sazonal; as respostas aos impulsos de chuva são menos sincrônicas e mais suavizadas e os tempos de pico e de recessão são mais longos. As análises que serão apresentadas a seguir permitem a quantificação destas características a partir da análise de toda a série temporal.

A autocorrelação e a análise espectral das saídas dos sistemas (ressurgências das Areias e do Lago) obtidas a partir do débito de um ano hidrológico são apresentadas na Figura 6. A forma das correlações mostra que o fluxo diminui lentamente no Lago quando comparado com a ressurgência das Areias. O efeito de memória é de 84,94 dias para o Lago e 3,5 dias para a ressurgência das Areias. O gráfico de densidade espectral mostra que a freqüência de corte é mais baixa para o Lago do que para as Areias. O tempo de regulação é de 68,96 dias para o Lago e 5,3 dias para as Areias.

Os espectros de ondeleta de Morlet dos débitos das ressurgências (Figura 7) confirmam as tendências apontadas nas análises anteriores. A ondeleta das Areias é caracterizada pela presença de componentes periódicos de 2 a 8 dias, descontínuos e de intensidade variável, típicos de sistemas que retornam rapidamente ao estágio pré-excitação. Este comportamento não está presente no espectro do Lago, onde as menores estruturas de freqüência (4-8 dias) são mais homogêneas com respeito à intensidade e relativamente mais contínuas. Em ambos os espectros pode ser observada, próximo ao período de 64 dias, a existência de um componente de intensidade relativamente alta, associado à estação que concentra as chuvas (primavera-verão).

Para a análise da relação impulso-resposta, a chuva horária foi atribuída como variável de entrada e a descarga horária como variável de saída. As FCC (Figura 8) mostram os tempos de resposta das drenagens aos impulsos de chuva que incidem sobre o planalto. O valor máximo da FCC ocorre após 10 h na ressurgência das Areias e após 53 h na ressurgência do Lago. Vale destacar que os valores são obtidos considerando precipitações de diferentes intensidades (a série temporal completa), portanto, representa uma estimativa global da relação impulso-resposta. Análises de impulsos individuais podem gerar valores mais altos ou mais 
Tabela 1. Síntese dos parâmetros monitorados.

\begin{tabular}{cccc}
\hline Pontos de monitoramento & Tipo de informação & Período de aquisição & Resolução \\
\hline Dolina das Areias & Precipitação $(\mathrm{mm})$ & Verão 2000 - Outono 2003 & $0,2 \mathrm{~mm}$ \\
Ressurgência das Areias & Vazão $\left(\mathrm{m}^{3} / \mathrm{s}\right)$ & Verão 2000 - Verão 2001 & $10 \mathrm{~min}$ \\
Ressurgência do Lago & Vazão $\left(\mathrm{m}^{3} / \mathrm{s}\right)$ & Outono 2002 - Outono 2003 & $10 \mathrm{~min}$ \\
\hline
\end{tabular}

A

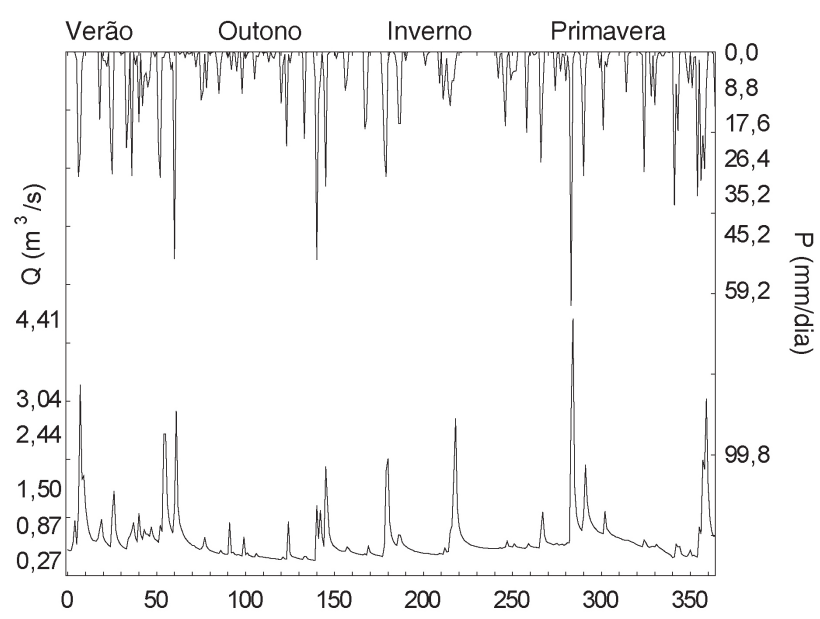

B

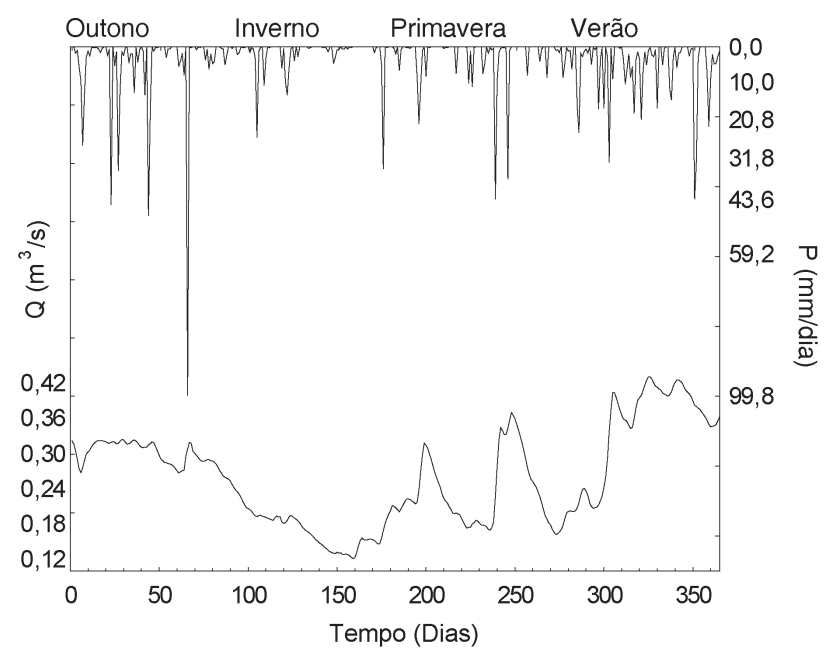

Figura 5. Chuva e vazão diárias para a ressurgência das Areias $(\mathbf{A})$ e ressurgência do Lago $(\mathbf{B})$.
A

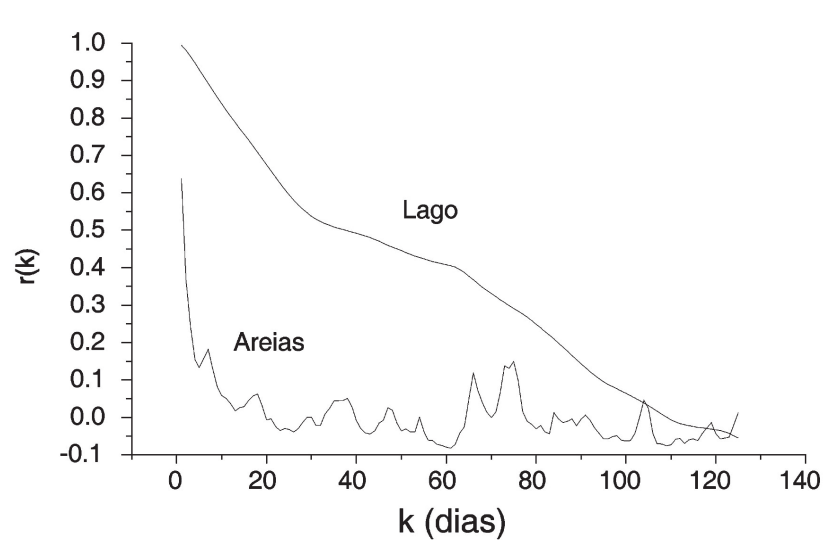

B

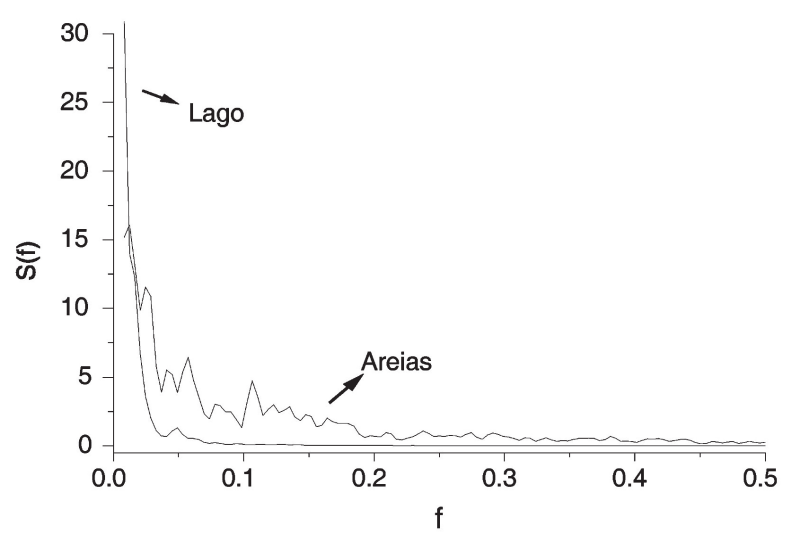

Figura 6. Funções de autocorrelação (A) e densidade espectral (B) para os débitos das ressurgências do Lago e Areias. 

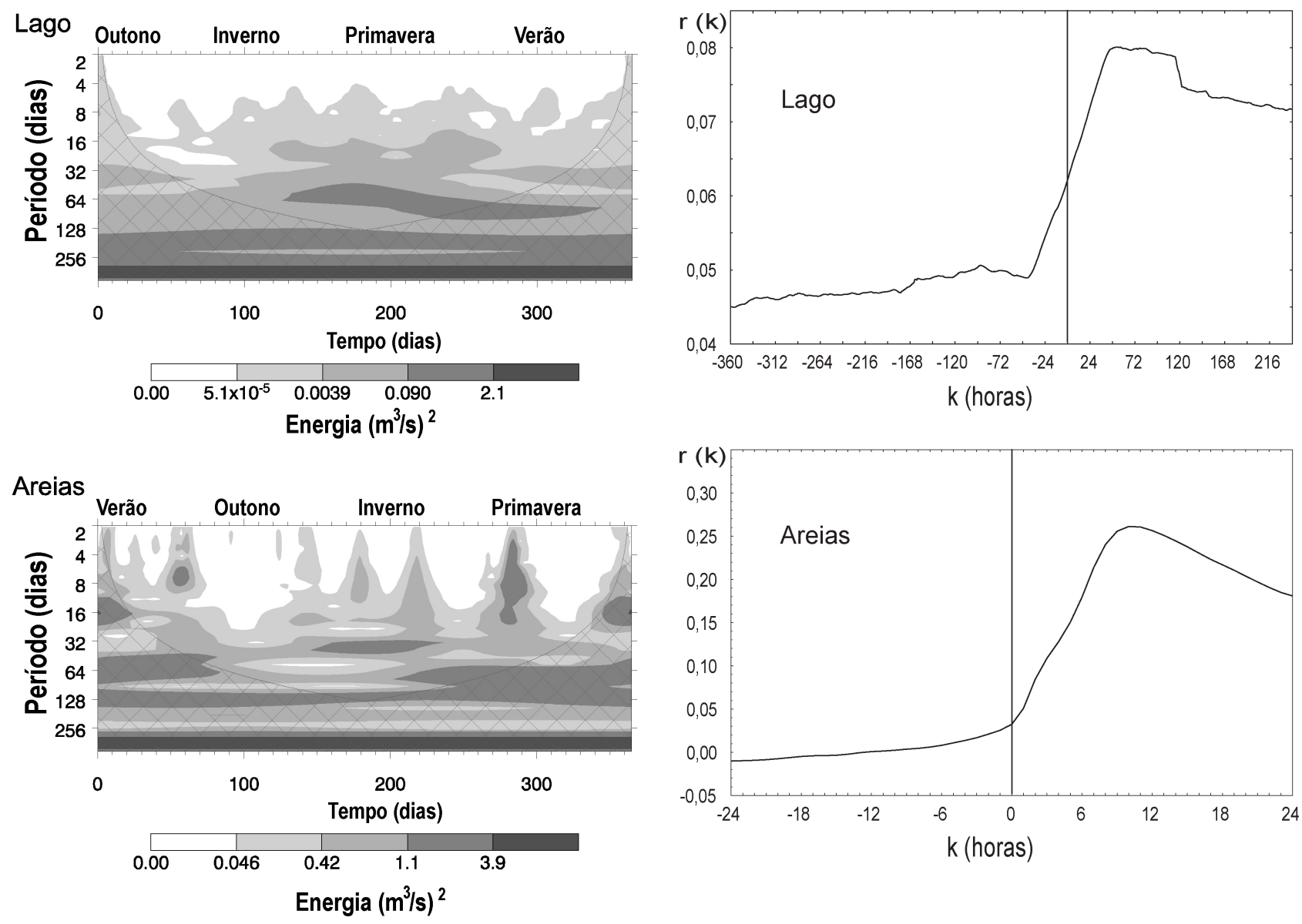

Figura 7. Espectros de ondeleta de Morlet para os débitos das ressurgências do Lago e Areias.

Figura 8. Funções de correlação cruzada da relação chuva vazão para as ressurgências do Lago e das Areias.

baixos que os obtidos, pois em sistemas com trechos vadosos, a onda de cheia comporta-se como uma onda cinemática, e quanto maior a onda, mais rápida ela será (Ford eWilliams, 1989).

A ressurgência das Areias apresenta o maior valor de $r(k)$ e um decaimento mais acelerado no correlograma quando comparado com a ressurgência do Lago. Esta característica indica pouca transformação do sinal de entrada e uma rápida drenagem para o sistema.

\section{DISCUSSÃO}

Todas as análises apresentam o Lago como uma drenagem mais inercial que a ressurgência das Areias. As considerações a seguir utilizam os modelos discutidos anteriormente para compreender esta diferença.

No planalto cárstico, a maioria dos riachos autóctones tem fluxo intermitente ou efêmero, os fluxos perenes mais

importantes provêm das drenagens alóctones. O sistema Areias é o que recebe o maior volume de água alóctone, característica que promoveu a formação de zonas de absorção bem desenvolvidas e a evolução de grandes cavernas. O sistema caracteriza-se pela recarga concentrada em pontos de absorção eficientes e escoamento através de condutos amplos. As constrições observadas ao longo do sistema (abatimentos em cavernas) e zonas de amortecimento das ondas de cheia (inundações em fundos de dolinas) não são suficientes para imprimir características inerciais significativas, como indicam os baixos valores de memória e de tempo de regulação e a rápida resposta aos impulsos de chuva.

As bacias alóctones que abastecem o sistema Córrego Fundo são de pequeno porte, e alguns pontos de injeção pouco desenvolvidos; certamente, muitos deles não conseguem absorver imediatamente o escoamento gerado por grandes eventos de chuva e devem amortecer ondas de cheia. As rotas mais carstificadas deste sistema ficam na 
zona de contato com os filitos, onde as bacias alóctones da Serra da Biquinha injetam água no carste. Nesta faixa estão alinhadas com a ressurgência do Córrego Seco, a Gruta Córrego Fundo e a Gruta da Paçoca. Nenhuma caverna conhecida está alinhada com a ressurgência do Lago. É possível que esta ressurgência seja a drenagem de uma parte do sistema que evoluiu a partir da recarga autóctone de setores do carste poligonal. Por ser uma área caracterizada principalmente por escoamentos superficiais temporários e dispersos em pequenos pontos de injeção, as rotas do fluxo subterrâneo são relativamente menos desenvolvidas e a recarga mais suscetível a variações sazonais. Os testes com traçadores mostram que em algum ponto do sistema, esta drenagem está conectada com a faixa mais carstificada que deságua na ressurgência do Córrego Seco. Este padrão distributivo do sistema também colabora para explicar o comportamento inercial da ressurgência do Lago. O Lago consegue dar vazão ao fluxo do sistema até certo limite e quando este é alcançado, o excedente é drenado pela ressurgência do Córrego Seco, que funciona como um vertedouro que amortece os débitos do Lago. Deve se considerar, ainda, que a ressurgência do Córrego Seco só é ativada com chuvas muito intensas ou após diversos dias de chuva, comportamento indicativo da existência de uma considerável capacidade de armazenamento. A combinação destes fatores é responsável pelo comportamento inercial da ressurgência do Lago, expresso pelos altos valores de memória e de tempo de regulação, por uma resposta lenta aos impulsos de chuva e o baixo valor de $r(k)$.

A defasagem entre impulso e resposta fornece uma estimativa da transferência de partículas e pulsos de pressão através do aqüífero. Esta informação é importante para estudos ambientais, pois pode ser utilizada para estimar o tempo de chegada de um contaminante numa fonte. O valor da FCC para o sistema Areias mostra que um fluxo carreado para o interior do aqüífero leva em torno de $10 \mathrm{~h}$ para atingir a ressurgência. Este valor é muito próximo do obtido num teste com traçador realizado durante um evento de chuva (Genthner, 2000). Neste teste, o traçador (300 g de rodamina) foi injetado num dos principais sumidouros do sistema ( $n^{\circ} 4$, Figura 3), e atingiu sua concentração máxima na ressurgência após 8,99 h. Num outro teste realizado nesta mesma rota, mas sem a ocorrência de chuva, a concentração máxima do traçador foi obtida após 18 h (Figura 9).

Dois testes quantitativos com traçador foram realizados no Sistema Córrego Fundo. O primeiro durante uma situação de estiagem (250 g de rodamina foram injetados), e o segundo, num período chuvoso, quando a ressurgência do Córrego Seco estava ativa (300 g de rodamina foram injetados). Em ambos os testes, o traçador não foi detectado nas amostras de água durante as $60 \mathrm{~h}$ de monitoramento. A passagem do traçador só foi provada com a análise de detectores

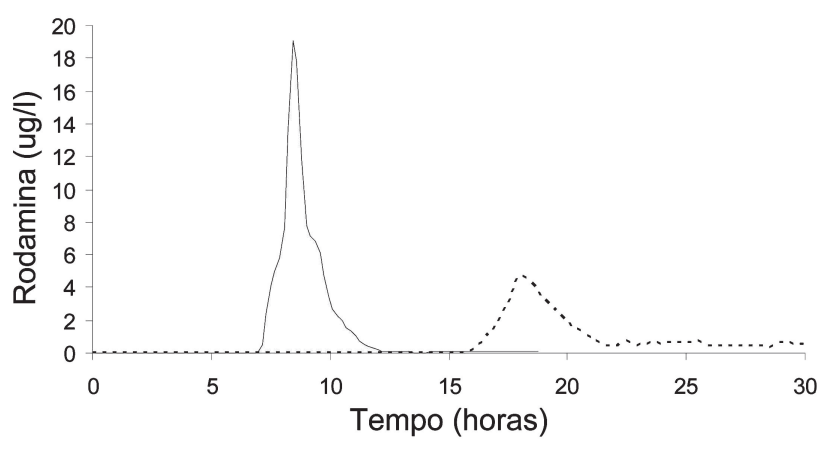

Figura 9. Resultado de testes quantitativos com traçadores na ressurgência das Areias (Genthner, 2000).

de carvão ativado coletados três semanas mais tarde. Em linha reta, as distâncias entre o ponto de injeção (nº 8, Figura 3) e as ressurgências (Córrego Seco e Lago), são menores que no teste realizado no sistema Areias. Os resultados sugerem a existência de alguma estrutura no aqüífero que promove um retardo ou uma importante diluição da pluma de traçador, comportamento compatível com o elevado valor obtido pela FCC (53 h) e com os parâmetros que indicam o caráter inercial do Sistema Córrego Fundo.

\section{CONCLUSÃO}

As ferramentas estatísticas empregadas para a análise das séries temporais destacaram atributos contrastantes no comportamento dos fluxos das ressurgências. No entanto, não podem ser utilizadas isoladamente para compreender as estruturas que controlam a circulação das águas. Sua integração com resultados de estudos com traçadores e com o mapeamento da morfologia das zonas de recarga e de cavernas mostrou-se fundamental para este entendimento.

A análise conjunta das informações mostra que o comportamento inercial da ressurgência do Lago, destacado pelas análises estatísticas, é conseqüência do padrão distributivo do sistema, de uma recarga mais suscetível a variações sazonais e a possível existência de um reservatório. As respostas rápidas observadas na ressurgência das Areias resultam de um sistema abastecido por pontos de injeção bem desenvolvidos, de uma circulação de água em extensos e amplos condutos que não promovem alteração significativa dos impulsos de entrada e de uma baixa capacidade de estocagem.

Os atributos extraídos das séries temporais correlacionam-se com valores de tempo de residência obtidos com traçadores (o sistema inercial apresenta tempo de residência mais longo que o sistema de respostas rápidas). Desse modo, a análise da relação impulso-resposta utilizando a 
FCC pode ser utilizada em sistemas hidrológicos similares, para substituir testes com traçadores na avaliação da circulação de partículas durante eventos de chuva.

Os resultados contribuem para o entendimento das heterogeneidades temporais e espaciais dos fluxos em sistemas cársticos e mostram que as análises das séries temporais devem ser parte das abordagens utilizadas para caracterizar a natureza do fluxo.

\section{AGRADECIMENTOS}

À Fundação de Amparo à Pesquisa do Estado de São Paulo - FAPESP, pelo financiamento da pesquisa (processo: 99/12672-4). Ao PETAR e a Pousada Rancho da Serra, pelo apoio logístico. Aos motoristas do IG-SMA, aos alunos Leandro Canaver, Fabrício e Ana Cláudia do IGc/USPe ao estagiário Adhin Santiago do IG-SMA, pelo apoio nos trabalhos de campo. Aos moradores do Bairro da Serra, Jurandir, Jamar e Edílson nossos guias na floresta, muito obrigado.

\section{REFERÊNCIAS BIBLIOGRÁFICAS}

Campanha, G. a. C. Tectônica, proterozóica no alto e médio vale do Ribeira, estados de São Paulo e Paraná. 1992. 296 f. Tese (Doutorado) - Instituto de Geociências, Universidade de São Paulo, São Paulo, 1992.

FORD, D.; WILLIAMS, P. Karst geomorphology and hydrology. London; Boston: Chapman \& Hall, 1989. 601 p.

Genthner, C. Aplicação do traçador fluorescente rhodaminaWT no estudo geohidrológico da área carbonática Lajeado-Bombas, Vale do Betari, sul do estado de São Paulo. 2000. 95 f. Dissertação (Mestrado) - Instituto de Geociências, Universidade de São Paulo, São Paulo, 2000.

GENTHNER, C.; FERRARI, J.A.; KARMANN, I. Identificação das áreas de recarga de fontes cársticas com o uso do traçador rodamina fwt (área carbonática Lajeado-Bombas, Iporanga-SP). Revista do Instituto Geológico, São Paulo, v. 24, n. 1/2, p. 11-23, 2003.

GROSMANN, A.; MORLET, J. Decomposition of hardy functions into square integrable wavelets of constant shape. SIAM Journal Mathematical Analysis, v. 15, n. 4, p. 723-736, 1984.

HALIHAN, T.; WICKS, C. M. Modeling of storm responses in conduit flow aquifers with reservoirs. Journal of Hydrology, v. 208, n. 1, p. 149-178, 1998.
JACQUET, J. Aspects généraux de la représentation mathématique des phénomènes en hydrologie de surface. La Houille Blanche, v. 2, p. 105-110, 1971.

JENKINS, G. M.; WATTS, D. G. Spectral analysis and its applications. San Francisco: Holden-Day, 1968. 525 p.

KARMANN, I. Evolução e dinâmica atual do sistema cárstico do alto Vale do Ribeira de Iguape, sudoeste do estado de São Paulo. 1994. 228 f. Tese (Doutorado) - Instituto de Geociências, Universidade de São Paulo, São Paulo, 1994.

KARMANN, I.; FERRARI, J. A. Carste e cavernas do Parque Estadual Turístico do Alto Ribeira (PETAR), SP. In:. SCHOBBENHAUS, C.; CAMPOS, D. A.; QUEIROZ, E. T.; BORN, M. Sítios geológicos e paleontológicos do Brasil. Brasília: DNPM-CPRM-SIGEP, 2002. p. 401-413. Disponível em: <http:// www.unb.br/ig/sigep/sitio043/sitio043.pdf>. Acesso em: 22 jun. 2006.

KIRALY, L. Modelling karst aquifers by the combined discrete channel and continuum approach. Bulletin d'Hydrogéologie, n. 16. p. 77-98. 1998.

LABAT, D.; ABABOU, R.; MANGIN, A. Rainfall-runoff relations for karstic springs. Part II: Continuous wavelets transform and multiresolution analyses. Journal of Hydrology, v. 238, n. 3, p. 149-178, 2000.

LAROCQUE, M., MANGIN, A.; RAZACK, M.; BANTON, O. Contribution of correlation and spectral analyses to the regional study of a large karst aquifer (Charente, France). Journal of Hydrology, v. 205, n. 3, p. 217-231. 1998.

MANGIN, A. Pour une meilleure connaissance dês systèmes hydrologiques à partir des analyses corrélatoire et spectrale. Journal of Hydrology, v. 67, n. 1-4, p. 25-43, 1984.

MANGIN, A. Karst hydrogeology. In: GILBERT, J.; DANIELOPOL, D. L.; STANFORD, J.; THORP, J. Groundwater Ecology. San Diego: Academic Press, 1994. p. 43-67.

MATHEVET, T.; LEPILLER, M.; MANGIN, A. Application of time-series analyses to the hydrological functioning of an Alpine karstic system: the case of Bange-L'EauMorte. Hydrology and Earth System Sciences, v. 8, n. 6, p. 1501-1064, 2004.

PADILLA, A.; BOSCH, A. P. Study of hydrographs of karstic aquifers by means of correlation and cross-spectral analysis. Journal of Hydrology, v. 168, n. 1-4, p. 73-89, 1995. 
SMART, P. L.; HOBBS, S. L. Characterisation of Carbonate Aquifers: a conceptual Base. In: THE ENVIRONMENTAL PROBLEMS IN KARST TERRANES AND THEIR SOLUTIONS CONFERENCE, 1986, Bowling Green. Proceedings... Bowling Green: National Water Water Well Association, 1986. p. 1-14.

TORRENCE, C. E.; COMPO, G. P. Apratical guide to wavelet analysis. Bulletin of the American Meteorological Society, v. 79, n. 1, p. 61-78, 1998.

ZARE, M. R. M.; NEMATOLLAHI, A. R.; SEDGHI, H. Application of spectral analysis of daily water level and spring discharge hydrographs data for comparing physical characteristics of karstic aquifers. Journal of Hydrology, v. 311, n. 1-4, p. 106-116, 2005. 